pect to see in the near future a considerable improve-
ment in lead cells in the way of longer life and greater reliability.

I think the investigations should be directed to methods for securing greater porosity and firmness in the proving the electrolyte so as to prevent the formation densities of the acid solution, so that it remains

Other metals will undoubtedly come into competitio with, and may displace, lead in batteries for tractio work, but as an auxiliary in electric light and power
stations lead cells will probably hold their own for some time.
Nickel is a strong metal compared with lead. Its peroxide belongs to that class of depolarizers which add electromotive force to the cell, and in this respect it is the best, so far, that it is practical to use in of steel for the grids and the containing vessel, and this gives a construction both light and strong. There seems
to be no reason to believe that this cell will not do to be no reason to believe that this cell will not do
what Mr. Edison claims for it. what Mr. Edison claims for it.
Silver would be a good metal to use in traction batteries if its cost were not so great. To be sure, the silver in a worn out battery would go a long way toward paying for a new set, but the first cost would be rather great. Silver is a rather abundant metal, and present, if the demand for it should sufficiently in In the lead cell the active material of the positive is only about half of the weight of the entire plate, so
the weight or silver oxide required in the silver cell would correspond to the weight of lead peroxide, and
not to the whole electrode. The other materials used would be inexpensive; nickel or steel for the positiv grid, and probably iron for both negative grid and active material.

Experiments indicate that a silver battery, giving the same power as a lead automobile battery weighing about 550 pounds, would require only about 70 pounds
of silver oxide and perhaps less. It would not take a very extraordinary reduction in the price of silver nitrate to make the cell practical from a financial stand-
point, and for the reasons given above such a cell could point, and for the reasons given above such a cell could be made to have a comparatively long life and high
efficiency, and would require but little attention to keep it in working order.

\section{PHOTO-ELECTRIC EXPERIMENTS}

By A. Fredierick Collins.

TIIE curious working out of another of Hertz's grea discoveries in wireless telegraphy has been exemplconi when he received signals a distance of 2,099 miles from Poldhu, Cornwall, while on board the "PhilaOn this trip it was found that the signals were distinct and clear at night for 2,000 miles, but in the day the effective distance at which the signals could
be deciphered was only a fourth part as great, or 500 miles.

In tracing this effect to its cause, one finds abun proper result. In 1887 roof that this is a normal an discharge on another had the effect of diminishing the spark of the latter, and upon careful analysis he de termined that this untoward result was due to the ultra-violet radiation-in which the disruptive dis-
charge is rich-dissipating the charge of the secondary oscillatory system.

The apparatus Hertz employed in his researches is shown in Fig. 1. It consisted of an ordinary Ruhm system, $\boldsymbol{B}$; a second and smaller induction coil of the same type, $C$, having a very small spark gap, $D$, was of both in alignment, so that the radiating propertie other will be in the best position to receive the waves. other will be in the best position to receive the waves. with a battery, $E$, and an interrupter, $F$, both of which

When the spark gap, $\boldsymbol{B}$, was screened from that of $D$ either by a conductor or an insulator, $i$. e., a metal or ebonite plate, the spark discharging across $D$ became much smaller. It was this fact which first excited Hertz's interest in the experiment; and in solvphysics is where his marvelous analytical genius was physics is where his marvelous analytical genius was
shown most splendidly. Had the spark been diminished by the intervention of the conductor and not the insulator, or vice versa, then the explanation could rostatic displacements, since there was a synchronous action between the coils, being operated on a common duced the same effect, reason proclaimed the retardation of the spark due to waves emitted directly from the spark of one falling on the other oscillatory system. It was reasonable to suppose that these were light waves. To test the validity of this supposition, Hertz arranged the oscillatory system separate and the This the physicist attributed to the dissipation of the electric charge on the balls of the oscillator. The
diselectrification of the charge on metals by light waves or rather radiation has been termed photoclaimed the attention of some of the leading physithe photo-eloctric effect of one spark on another was concerned. He tested the influence of sparks between
knobs, points, and other forms of terminals forming the spark gap; he employed short, straight sparks and long jagged sparks, the faintly luminous blue sparks, and the brilliant white sparks; he found that sparks of
only 2 millimeters in length possessed the property
of diminishing the secondary electric sparks at a distance of 15 or 20 centimeters.

Hertz showed that glass cuts off the photo-electric
effect and this led him to suspect that it was not effect and this led him to suspect that it was not
the visible waves of light that possessed the photo- electric property, but the extremely rapid invisible
ultra-violet radiation. When the glass tube allowed the minutest spark to be exposed at either termina the effect was instantly reproduced. The maximum ef fect was obtained by short sparks between balls of were tried, but Hertz found no appreciable difference; the only conditions seemingly to be fulfilled were persparking distance not too great. primary and secondary sparks was reciprocal, the disruptive discharge of one acting on the disruptive
discharge of the other. In further demonstrating that

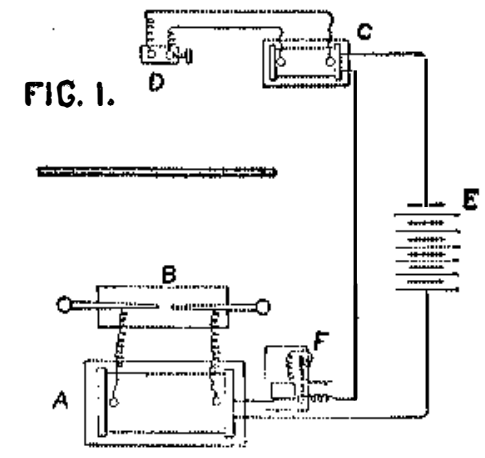

TOP ELEVATION OF APPARATUS USED BY HERTZ IN HIS RESEARCHES IN PHOTOELECTRIC EFFECTS.

he photo-electric effect was not caused by the visible violet radiation, he interposed pieces of mica and glass-opaque to ultra-violet waves-between the prieffect, the results were $n i l$, yet both of these substances to longer waves of light.

fication of the changed oscillatory balls showed thi they also possessed photo-electric properties, although the faintly luminous spark of the induction coil was the faintly luminous spark of the induction coil was
a great deal more effectual since it is a much richer
source of ultra-violet waves. Hertz tested the sunsource of ultra-violet waves. Hertz tested the sun light for photo-electric effects many different times of the greater interest to the recent experience of Mar-
coni.

After Hertz, Prof. Auguste Righi-the preceptor of

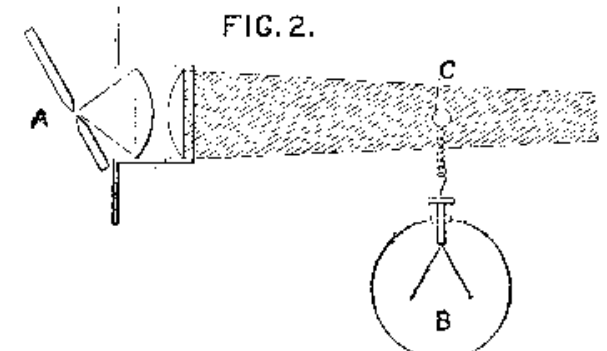

RIGHI'S APPARATUS FOR SHOWING PHOTO. ELECTRIC EFFECTS

Marconi-took up the work and his researches resulted in demonstrating that the greatest photo-electric ef-
fect was produced by an arc light, the electrodes of
which were formed of rods of zinc; in accordance with Hertz, Righi was unable to discover the slightest influence $\in$ xerted by the sun's rays. Righi found that the charge of copper gauze and zinc plate would be reduced under the radiation of ultra-violet light, and with a number of elements so formed, he constructed a photo-electric battery. He also observed its effect in
discharging charged insulators of ebonite and sulphur. The hypothesis Righi favored in accounting for this phenomena was that the ultra-violet radiation protive electricity, the molecules of the air acting as carriers for the minute charges. According to this hypo-
thesis the particles of air carry definite charges of

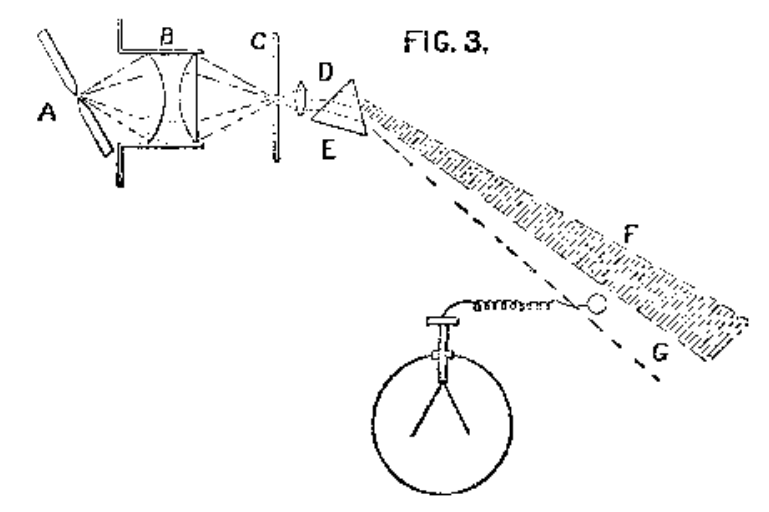

LODGE'S APPARATUS FOR SEPARATING THE ULTRA-VIOLET RADIATION FROM THE VISIBLE LIGHT WAVES.

negative electricity, and when these traverse certain paths they cast electric shadows, just as they do in a
Crookes shadow tube. Righi determined that an insulated metal is charged to the positive sign by ultraa small initial plus-charge at metal is neutral or ex periment. By employing a more sensitive method of detection than Hertz, Righi found the discharging ef greatest when the spark gap was formed with te minals of zinc or aluminium. Righi assumed the reason for the failure of sunlight to produce photophere fic effects to the absorbing action of the atmosresearch it' is evident that the sun produces a very appreciable action, but that sensitive instruments are
required to detect it. In reproducing these experIments, an easy and effectual method may be contrived making the tests.

an. 2 shows the arrangement of the apparatus. A troscope to which a of zinc rods, $\boldsymbol{B}$ a gold-leaf electached by a wire. Let the ball be charged with nega-
tive electricity, and then expose it to the rays of the arc lamp; almost instantly the leaves of the electroscope will converge, showing that the charge is dissipated; but let the ball be charged positively, and the
experiment reproduced; it will be found that no appreciable decrease of the charge takes place. To demonstrate more clearly that this discharging
effect is due to the action of the invisible ultra-violet rays, Lodge used the combination of apparatus as shown in Fig. 3. A represents the zinc-rod arc-lamp, $B$ a pair of plano-convex condensing lenses of quartz, $C$ a
diaphragm, $D$ an objective convex quartz lens, and $E$ diaphragm, $D$ an objective convex quartz lens, and $E$
a quartz prism. The shaded portion, $F$, shows the path of the visible rays, and the unshaded portion, $G$, in-
closed in the dotted lines, represents the invisible ultraviolet radiation. Now the instant the negatively
charged zinc ball is placed in the line of the ultraviolet radiation, the phenomenon of photo-electric ac-
tion is apparent, the drop of the leaves of the electroscope showing the charge has been carried away. While Hertz and Righi failed to observe the photo-
electric effects of sunlight, Elster and Geitel succeeded, and have been able to exhibit not only the dissipating influence of the direct rays of the sun, but of diffused daylight. The apparatus with which this experiment was accomplished consisted of a zinc dish 20 centi-
meters in diameter and well insulated; this was connected to a quadrant electrometer and charged pega. tively, in the dark, to a potential of 300 volts, when it
was exposed to the action of the sunlight; the test
showed a drop in voltage to 0 in 60 seconds, whereas a positive charge was retained for a very long time. The leakage of negative electricity from the dish when in the dark was practically eliable drop in potential. action relating to the checking of magnetism on the dissipation of an electric charge in rarefied gases, on in which, however, vacuum tubes play important rôles; subject of photo-electric action in wireless telegraphy,
at least at the present time. It has been shown that silver and copper plates require a much stronger ultraviolet radiation before any dissipating discharge takes
place than the other metals, while zinc and aluminium place than the other metals, while zinc and aluminium
have a photo-electric sensibility even for blue light. have a photo-electric sensibility even for blue light.
It would seem then that the antennæ in wireiess telegraph installations could be insulated with a glass sheath, which would cut off the ultra-violet radiation; or that if copper were employed for the sending and
receiving antenne, the dissipation would be very much
reduced It would be an interesting experiment to as. reduced. It would be an interesting experiment to asthe ultra-violet radiation would have upon comme cial wireless telegraph apparatus. At all events, it is
evident that oceanic cableless telegraphy will be productive of some wonderful modifications in the present ains will take the place of the mol paratus is constructed to transmit a cableless message a distance of 2,000 miles instead of the short distance covered by miniature laboratory sets that have already

\section{THE SAFETY MATCH PROBLEM.}

THE city of New York intends to make the use of the fire Department's view of the case has been presented in the public press. The opinion of a match manufacturer
Mr. William E. Williams, of Chicago, Ill., may, there fore, not be without interest.
Mr. Williams says that in the matter of the dangers attending the use of parlor matches there is much suthe heads of parlor matches and thereby ignite them The only material in the head of a match which is worth eating, is the glue; and glue is not inviting when compounded with ground glass, flint and foul
smelling chemicals. Animals have a particularly fine smelling chemicals. Animals have a particularly fine sense of smell. For that reason they avoid matches.
No one, says Mr. Williams, ever heard of a mouse's No one, says Mr. Williams, ever heard of a mouse's in order to get at whatever glue might be contained glue. He tells us that he had a desk drawer almost filled with sample matches of all kinds. Attracted by the remains of a lunch that had been hidden in the drawer by an office boy, the mice entered and gnawed pasteboard of the match boxes was completely gnawed away; and yet the match heads were not ignited. In the matter of accidental ignition of a parior
match, Mr. Williams points out the well-known fact that the noise produced always gives the alarm. Any safety match will ignite by heat and by friction noise is produced.

Economically considered, Mr. Nilliams holds that the parlor match is far cheaper and better than its rival a light from a safety match. Furthermore, safety matches of necessity are packed in small boxes holdin on an average not more than 35 matches, while for age box. The box for the safety matches is heavier and more expensive. Safety matches, says Mr. Williams, are of necessity packed in small boxes and are always accompanied by the box. Furthermore, the manufacture of parlor matches in the United States has advanced to such a stage of perfection that foreigners
can no longer compete with us; but in the manufacture 